\title{
Learning on Gaming: A New Digital Game Based Learning Approach to Improve Education Outcomes
}

\author{
Sabina Maraffi \\ University of Camerino, Camerino, Italy \\ Francesco M. Sacerdoti \\ e-voluzione srl, Naples, Italy \\ Eleonora Paris \\ University of Camerino, Camerino, Italy
}

\begin{abstract}
Educational technologies that use more suitable tools to help students improve the teaching-learning process: games and video games are excellent educational vehicles. The project GeoQuest is a class-interactive role-playing computer game - computer class role plating game (CCRPG), to teach inter-disciplinary science and humanities. The students interact with the game using their own smartphone or tablet and the system collects the individual answers. Game paths, such as several activities, videos, animations, and hands-on activities, to incentivise different perception channels and multiple communication codes. GeoQuest is a new teaching approach designed for learning on gaming (LoG) to learn while playing, different from edutainment (educate and entertain together) and gaming to learn (playing a game without specific didactic). With LoG, the game "hides" didactic inside the game. The CCRPG allows a significantly greater attention, with a persistent attention during the whole game. This improves learning processes, and at the same time, renew teaching competences of mentors integrating information and communications technology (ICT), storytelling, and digital game base learning (DGBL) with an ease of realise new didactic product. Keywords: learning on gaming (LoG), digital game based learning (DGBL), storytelling, innovative teaching, role-playing game, interactive teaching
\end{abstract}

\section{Introduction}

European Union (EU) gives great importance to a higher education quality, since the knowledge and the skills of its tomorrow citizens depend on education quality and hence to rise European competitiveness.

In analysing the needs, European Education Regulations are clear and precise in using learning levels and the skills acquired by students in all European countries and abroad. The education guidelines, focused by EU Commission, are perfectly in line with the world's leading educational instances: innovative teaching, information and communications technology (ICT), hands-on activities, labs activities, etc..

An innovative teaching technology combines ICT, traditional and new media, and social networks, where the game is a key element. An excursus on the relationship between game and education is reported in order to

Sabina Maraffi, Ph.D. candidate, professor, School of Science and Technology, University of Camerino.

Francesco M. Sacerdoti, professor, CEO of e-voluzione srl.

Eleonora Paris, professor, Geology Department, University of Camerino. 
identify the most appropriate use of gaming for educational purposes.

The goal is the application of learning on gaming (LoG) and a new digital game based learning (DGBL) approach, to create innovative educational games and new educational materials for teachers by using a learning environment with game mechanisms to enhance engagement and acquisition of skills and to improve education outcomes. The research questions are as the following:

1. Could digital games foster the skills acquiring?

2. Could computer games be a vehicle for learning "in situation"?

3. Could role-playing games support personalised learning?

4. Could game based learning motivate teachers and renew teaching?

5. Does game based learning have to be limited to a specific school age range?

\section{Theoretical Background and State of the Art}

Chapman and Rich (2017) claimed that games might encourage students to spend more time in studying, be more engaged, and as a result, learn more.

Educational gamification, which is the use of game elements in non-game contexts, improves learning experiences, engaging the students in a social, emotional, and cognitive level. The use of student-centered game elements in non-game educational systems improves student experience, drives engagement with learning activities and models, teaches effective learner skills, and enhances student attitude and identity as a learner (Jantke \& Hume, 2015).

To motivate the human players to engage in knowledge and skill acquisition, some appropriate game design is necessary (McGonigal, 2012).

DGBL

A significant learning experience by a player requires a challenge that is well suited to skill level and a system that give immediate meaningful feedback. This represents an argument in favour of personalised learning (Mayo, 2009).

Challenge and skills are high and in balance-Individuals stretch their skills to the limit looking for a challenging goal. The various combinations of high and low challenges and skills predict distinct psychological states: (a) apathy, resulting from low challenge and low skill; (b) relaxation, resulting from high skill but low challenge; (c) anxiety, resulting from high challenge but low skill; and (d) flow, resulting from high challenge combined with high skill (Csikszentmihalyi \& Schneider, 2000).

Game designers should emphasise challenge and engagement, while considering players' skills, which also contributes to the engagement and immersion. Vygotsky (1978) believed that learning occurred within a learner's zone of proximal development (ZPD). From the activities, a learner can independently master to those challenges, which can be accomplished with the help of additional supports. Offering activities inside the players' ZPD will create a more appropriate challenge to their skill level than keeping them maximally engaged and in learning (Hamari et al., 2016).

Research has explicitly related the sense of presence, being there, immersion, or flow in different virtual reality interfaces with positive learning outcomes (Abrantes \& Gouveia, 2012; Fassbender et al., 2012). Research also suggests that higher the challenge, greater the engagement, or sense of immersion (Vygotsky, 1978). Considering students' high comfort level with smart devices and gaming, leveraging portable devices for education could have a positive impact on student interest and engagement (Bursztyn et al., 2015). 
Students collaborate and discuss their ideas and possible solutions, and then, connect with other students around the world. This new way of learning offers new opportunities to use collaborative tools, allowing the students to co-construct efficiently knowledge (González-González, Collazos, Guerrero, \& Moreno, 2016). If the collaboration process is improved, the quality and quantity of topics learned by the group will be increased (Marty \& Carron, 2011). Results indicate these DGBL increases student motivation to pursue geoscience learning (Bursztyn, Shelton, Walker, \& Pederson, 2016).

LoG

The LoG is a new teaching approach aimed at learning while playing. Gaming to learn (McGonigal, 2012) consisted on playing a game without specific didactic to enhance knowledge (Maraffi \& Sacerdoti, 2016) and is an approach in which the game is the main focus. In LoG, didactic is hidden within the game. The didactic contents are designed specifically for the game and integrated with each other. LoG could improve the students' learning levels and their acquiring skills, and at the same time, could renew the teaching competences.

\section{Research Design}

This work concerns a specific research project - the application of LoG as the best methodology to improve teaching and learning processes. This project is based on a new didactic methodology - a computer class role-playing game (CCRPG). The game specifically developed for the research is GeoQuest. This game is designed by the author together with a specialised software company "e-voluzione srl" in Naples, Italy (Maraffi, Scamardella, \& Sacerdoti, 2015).

\section{GeoQuest}

GeoQuest is a computer class game that recreates a virtual reality in which players advance all together without knowing the path (Maraffi \& Scamardella, 2016) as a typical adventure game. The game requires a single computer, which displays on a whiteboard the adventure pathway to the whole class. The players are guided by a narrator voice (game master) that accompanies them through the story. They live an unknown outcome experience that changes every time according to players' choices. The use of a narrator voice, together with the subtitles, enhances the integration of students. The voice can be also slowed down to simplify participation and increase comprehension of the story to "non-mother-tongue" students.

The game is realised as a two-dimensional (2D) adventure game projected on the wall and controlled by the players with a simple browser on their smartphones or tablets, connected via local area network (LAN) and does not require any Internet connection. The computer game plays as a "web server" for the students and the local web page works as an "answering machine" (see Figure 1).

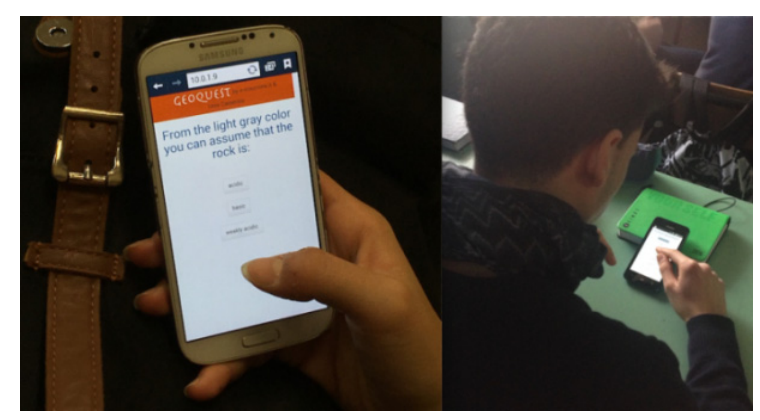

Figure 1. Players interact with the software with their own smartphones. 
The players' answers are evaluated by the game with the criterium of "majority voting system" to decide "what the class wants." GeoQuest's world is created with drawings and pictures, musics, sound effects, videos, and animations, realising an atmosphere for a full and complete immersion into the game (Maraffi, Sacerdoti, \& Scamardella, 2016) (see Figure 2).

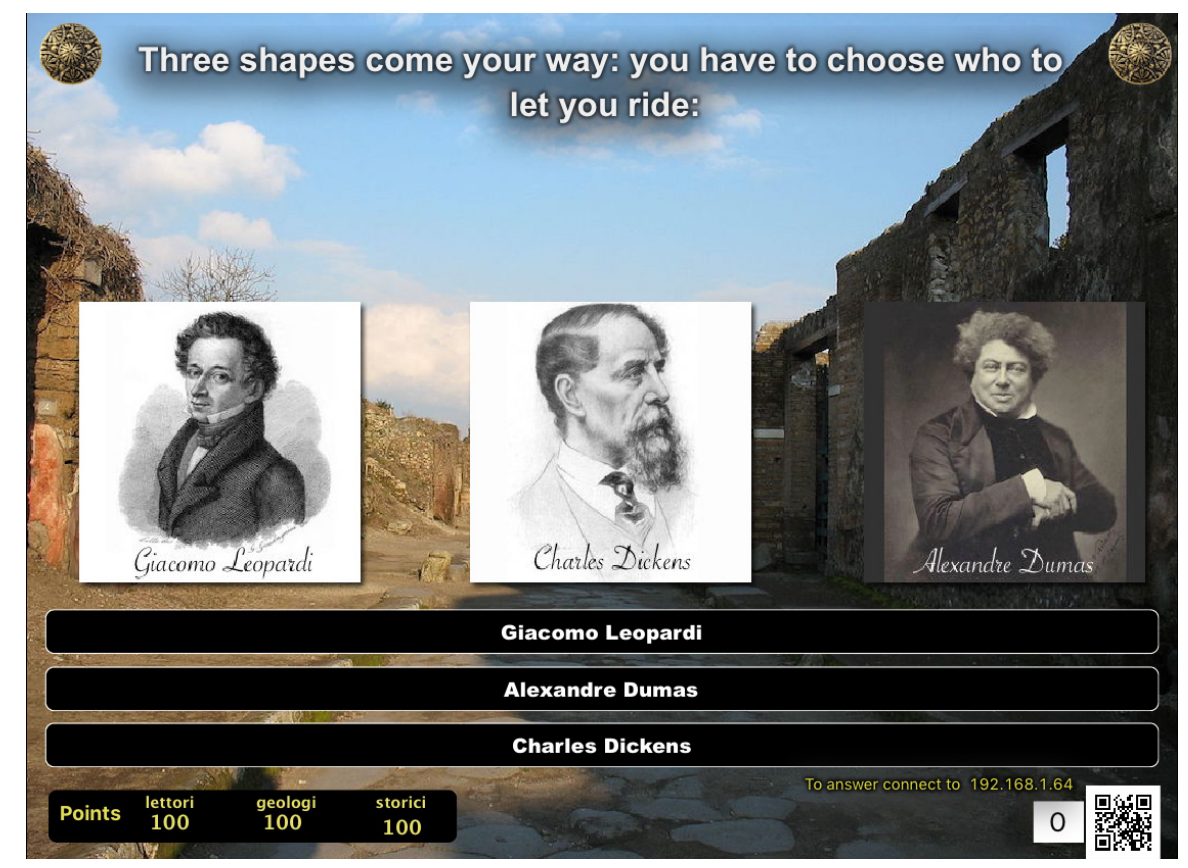

Figure 2. An example of the GeoQuest interface.

This in order to accomplish the acquiring of learning and skills through authentic task-An assignment given to students is designed to assess their ability to apply standard-driven knowledge and skills to real-world challenges.

To move on their paths, players have to answer some questions. Each player, depending on the role they chose at the beginning of the game, claims specific skills and competences to deal with the questions. Their response will have a different weight on the total score.

Adventures include laboratory activities that can either be made in classrooms or in labs, while playing the game or be viewed on specific recorded videos (Maraffi et al., 2016a, 2016b; Maraffi, Ercolino, \& Sacerdoti, 2017). GeoQuest adventures are played with e-voluzione role playing game engine (EVO-RPGE), an innovative engine which realises the role-playing game in the classroom (Sacerdoti \& Maraffi, 2015). One of the most innovative project features of EVO-RPGE is the easy adaptation of adventures to different stories, contents, and languages (Sacerdoti \& Maraffi, 2015).

The CCRPG applies the digital storytelling approach to the adventure games, giving the possibility to the whole class to play all together. As Plato did with his stories to simplify complex concepts, or as Jesus Christ did with the parabolas, writing an adventure game can simplify disciplines and create links among them. We are realising a powerful tool to let students and teachers themselves create new stories that are to be played by other classes. The engine has been designed to easily create multiple-language versions of the same story. This can allow a wider diffusion of the stories also among different countries. Creating adventure stories, as well as living them, enhance mastering acquired knowledge and skills. 


\section{Learning Environment}

How to realise a "role game" for a whole class playing together? Jantke and Hume (2015) tried to develop some methodology wrapping real learning content into attractive virtual worlds. In a digital role-playing game, the characteristics of the virtual world must assign meaning to places, actors, and actions.

In classic role-playing games, each player has a specific role with specific characteristics and virtual skills, and each player follows his/her avatar as a single entity. The avatars sometimes collaborate with each other to reach a specific goal, but it is not mandatory.

The game is designed to be played by the whole class, and to foster collaborative learning, we created a group-role game (every player choose a group to participate with) and the relative role characteristics. Furthermore, the class players move all together through the path. The learning environment helps collaboration among all players. Students engaged in group competition enhance learning (Hamari et al., 2016).

What type of stories? The difference between the narratives found in digital games and those found in other media, such as books and movies, changes the level of engagement. In other media, the person engaged in the narrative is seen as a passive consumer and has no impact on the outcome of the narrative. An illusion is created whereby the players of a game perceive themselves as constructing the narrative of that game (Cohen, 2016).

In a good computer or video game, you are always playing on the very edge of your skill level and always on the brink of falling off. When you do fall off, you feel the urge to climb back on. That is why there is virtually nothing as engaging as this state of working at the very limits of your ability (McGonigal, 2012). There is evidence that fantasy through simulations and games promotes intrinsic motivation and can enhance learning compared to instruction without fantasy elements (Lepper \& Hodell, 1989; Parker \& Lepper, 1992).

What kind of graphical representation? Our game is based on a 2D-learning environment to allow cooperative group playing. Because the use of three-dimensional (3D)-learning environment imposes the player to control an avatar that walks alone and independently through the story, creating contiguous solitudes that obstruct the group and the teamwork. This would let players lose the spirit of collaboration between them, at the detriment of inclusion, and would lead to boredom in the end. Hwang, Chiu, and Chen (2015) asserted that there are several reasons for choosing the 2D system:

1. It is good enough for presenting the required gaming scenarios;

2. It requires less computing power;

3. It avoids situating school students in a complex 3D interface, which may increase the difficulty for them to learn through the game.

Effective game-based learning should provide a 2D learning environment, immersive, and digital made. The design takes advantage of the benefits of games that provide immersion-in-context, rewards for correctness, and immediate feedback in response to student interaction (Bursztyn, Shelton, Walker, \& Pederson, 2016).

\section{Methodology}

In Table 1, the features of the CCRPG are summarized (Maraffi \& Paris, 2017). The objective of the first research phase was to develop the GeoQuest prototype with three adventure paths, different for themes, and ages of target students, but all focused on scientific topics. 
Table 1

GeoQuest Project's Characteristics

\begin{tabular}{|c|c|}
\hline Characteristics & CCRPG \\
\hline Immersion & $\begin{array}{l}\text { Narrator speaking voice, sounds effects, photo, original designs, and musics, create a totally } \\
\text { immersive environment. }\end{array}$ \\
\hline Engage & Thanks to storytelling, mystery, and suspense. \\
\hline Changing environments & Adventure pathways change depending on the players' choices. \\
\hline Mystery & Each path may have a different finish and fantasy is blended with real world. \\
\hline Shared experiences & All players follow game on the same multi-medial whiteboard or other screen. \\
\hline Cooperative learning & Shared experiences foster cooperative learning. \\
\hline Lab & Possibility to have lab activities or watch related videos. \\
\hline Immediate feedback & $\begin{array}{l}\text { Game engine indicates immediately whether the answer provided by the player is correct or } \\
\text { wrong. In the latter case, the exact answer is indicated. }\end{array}$ \\
\hline Interactivity & Players interact with the game trough their own smartphones or tablets, using a LAN. \\
\hline Interdisciplinarity & Science topics are treated with humanities. \\
\hline Multi-language & Adventures pathways available in any language. \\
\hline Inclusion & $\begin{array}{l}\text { Accessible design creates an inclusive educational environment: different communication codes } \\
\text { (video and audio), notebooks. }\end{array}$ \\
\hline User friendly & Software is specific for this CCRPG and it can also be used by non-experienced teachers. \\
\hline
\end{tabular}

In the second phase, a first experimental test was carried out with the aim to:

1. Calibrate and evaluate the impact and effectiveness of our CCRPG methodology in order to make all the necessary changes to the learning environment: software characteristics, player interactions, game features, and enhancement to the stories already completed (processing and improvement step);

2. Verify applicability in different situations, school types, class types, and student ages;

3. Develop a rigorous experimental protocol to be used in the third phase of the research project;

4. Perform a first qualitative experimentation.

In the third phase, not performed yet, a definitive quantitative experimentation and data analysis will be executed, followed by the realisation of the final version of the game engine.

\section{First Experimental Tests}

\section{Instruments}

CCRPG GeoQuest has been experimented in some classes, using a personal computer and an interactive whiteboard (IWB). The students were able to interact with the game through their own smartphones or tablets with a simple browser connected to the game via LAN.

Three different adventures pathways has been realised and each related to different students' ages:

1. SoilQuest (Maraffi et al., 2016a; 2016b) for students aged 8-12;

2. Geoquest Phlegrean Fields (Maraffi, Scamardella, \& Sacerdoti, 2015) for students aged 13-18;

3. GeoQuest Vesuvius (Maraffi, Sacerdoti, \& Scamardella, 2016) for students aged 17-21.

\section{Research Population}

There are 26 class groups, six of which aged 8-10, seven aged 11-14, 12 aged 14-18 (different school types), and one university group.

\section{Language}

It has been conducted an experimentation in students' mother-tongue language (Italian) and some 
experimentation in English (to test the game on content and language integrated learning [CLIL] approach).

\section{Data Collection Tools}

For each group of classes that carried out the same adventure path, other two control groups were provided. The former with only frontal teaching activity and the latter with multi-media didactic activities supported by PowerPoint (PPT).

The contents covered were the same between the experimental and control classes. Pre- and post- test surveys were conducted for students and teachers, on customer satisfaction, and on acquired skills (Maraffi \& Sacerdoti, 2016).

We proceeded with interviews - all of the teachers, 40 students randomly chosen, and 75\% of schools' headmasters. The numeric answers were scaled from 1 to 10 . The feedbacks not expressed numerically have been reported in numerical evaluations, using conversion grids between the number of positive factors and voting (e.g., "predominantly negative factors" = less than 5 and "prevalence positive factors" = higher than 5).

\section{Analysis Approaches}

The processing of the experimental data has been prepared following criteria of brevity, readability, and reliability. The experimental protocol developed aims to turn the questions into more concise and readable ones, eliminate redundant or insignificant elements, and ensure relevance to the reported data.

Refer to a previous work of the authors to thoroughly explore the experimental protocol and collected data (Maraffi \& Sacerdoti, 2016).

\section{Results}

Only qualitative data are now available, as well as some quantitative data was analysed in the second phase of the research to refine the experimental protocol. The final quantitative data will be analysed in the final phase of the research. The qualitative data collected were processed according to the methodologies indicated in the literature (Martínez-Rodríguez, 2011; Martínez-Godínez, 2013) and related to the research questions.

A first interesting result is highlighted by the pie graphic representation of global average in Figure 3 (Maraffi \& Sacerdoti, 2016) about didactic methodologies. We considered in the evaluation the participation, the comprehension, the ability to convey complex topics, and the ability to learn a foreign language.

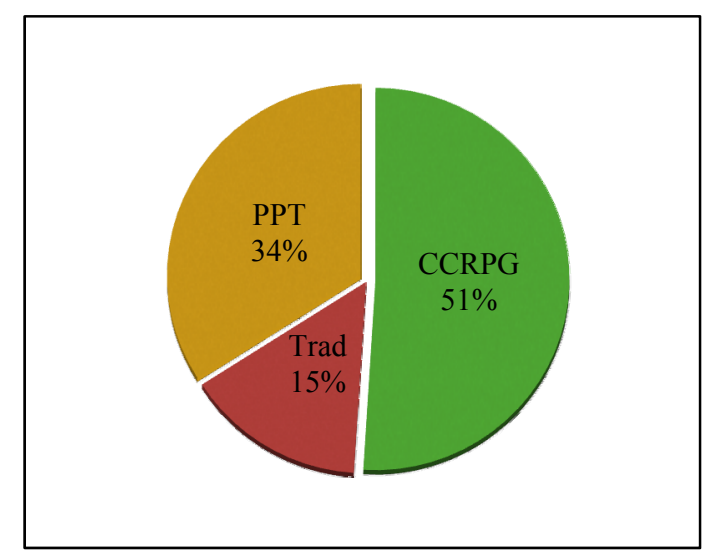

Figure 3. Students approval of three different teaching methodologies: CCRPG, PPT supported lesson, and traditional (frontal) lesson. 
The first quantitative results are shown in Figures 4 and 5 (Maraffi \& Paris, 2017). They derive from the comparison between right answers obtained in the pre-tests and right answers obtained in post-tests. Pre- and post- test contained the same questions and were given immediately before and immediately after the teaching activities.

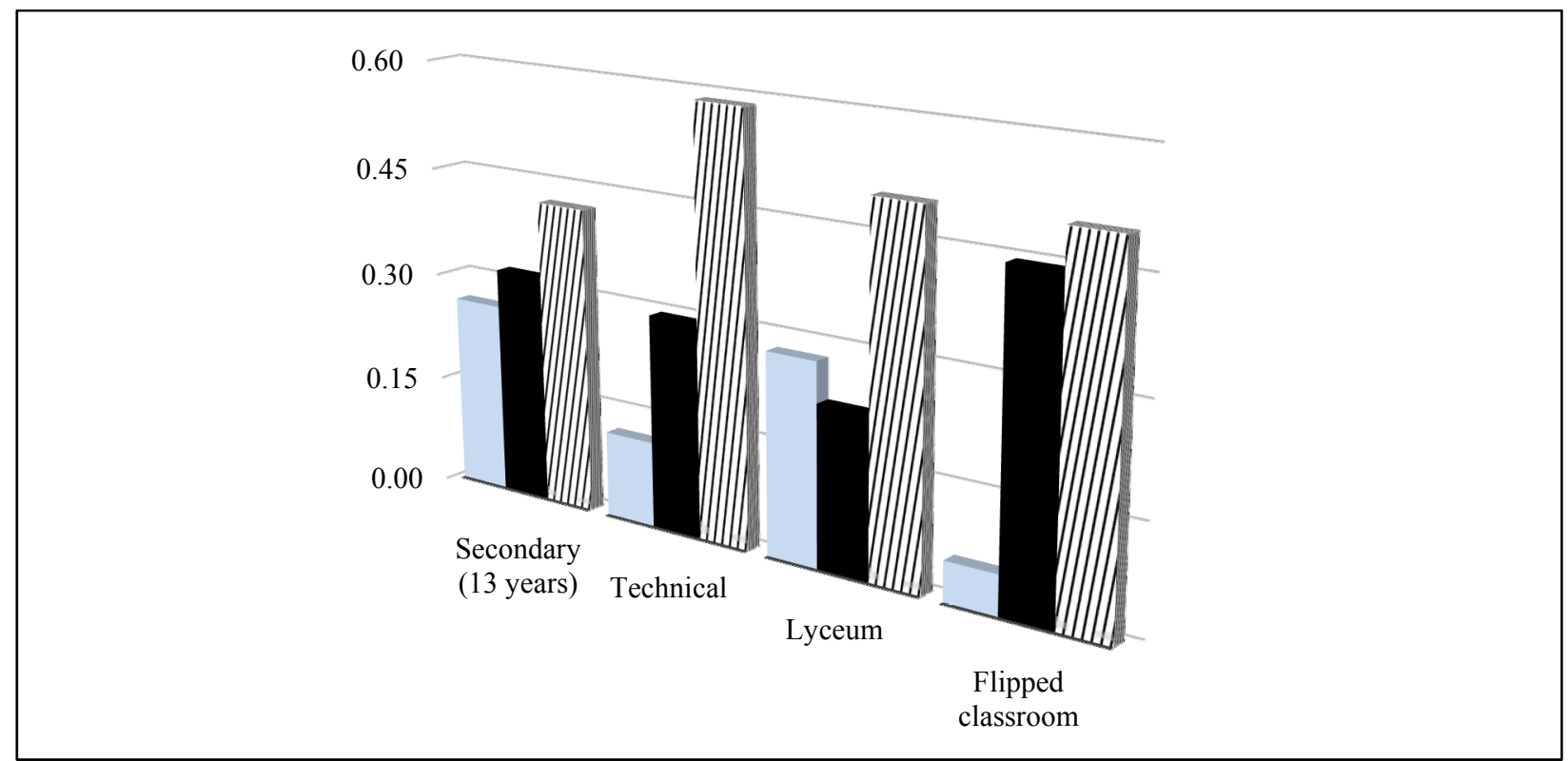

Figure 4. Percentage right answers post- and pre- test, measured after frontal teaching activity (tint color), after multi-media teaching activities supported by PPT (dark color), and after GeoQuest teaching activities (stripe), respectively in secondary school (aged 13), in technical high school, in lyceum high school, and in a classroom with "flipped" teaching approach.

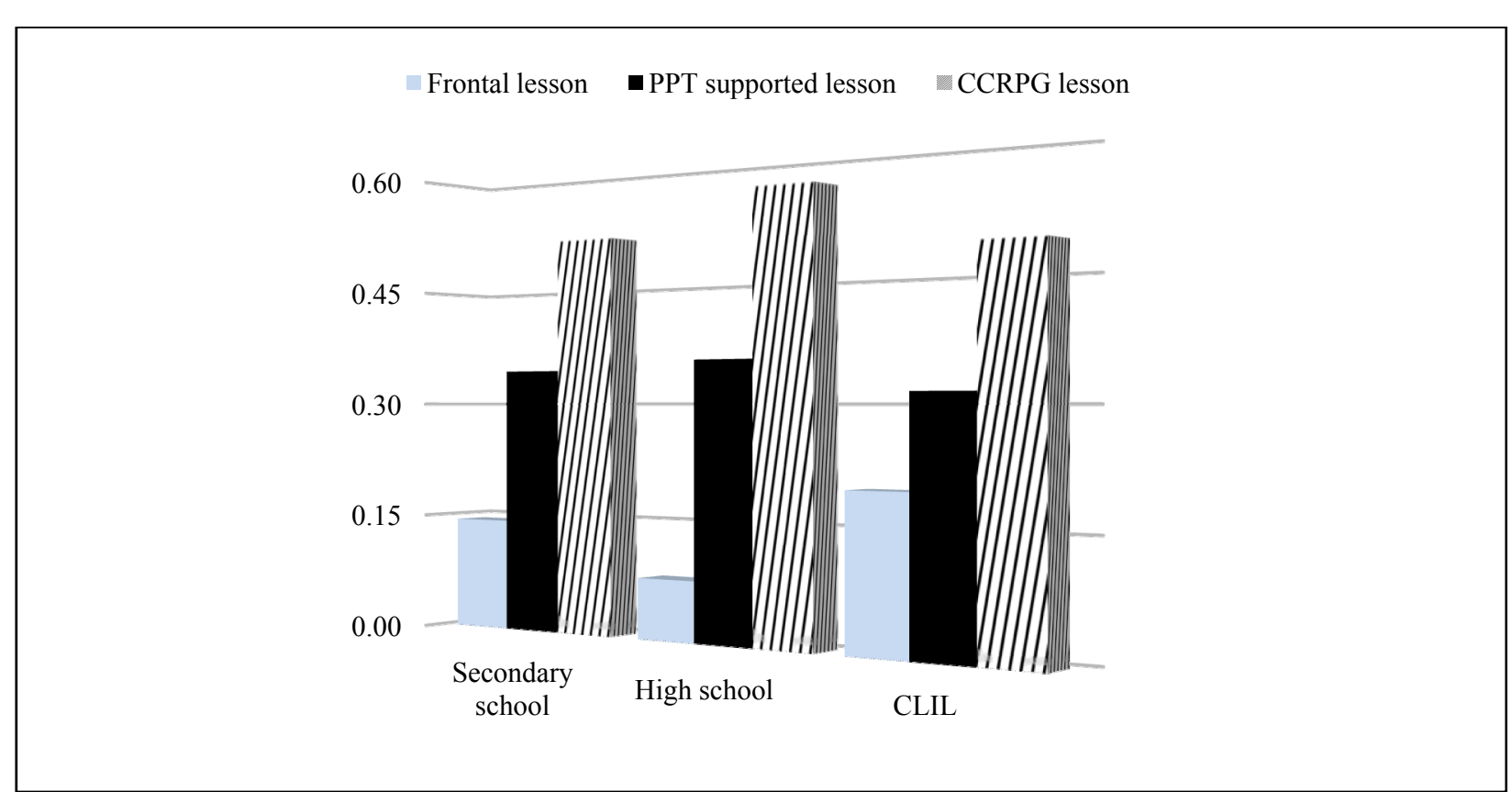

Figure 5. Percentage of right answers post- and pre- test, measured after frontal teaching activity (tint color), after multi-media teaching activities supported by PPT (dark color), and after GeoQuest teaching activities (stripe), respectively in secondary school (aged 13), in high school and in all cases with CLIL approach. 
After experiencing SoilQuest (Maraffi et al., 2017), students demonstrated a high level of concentration in their didactic activity applied with the game and also a more emotional involvement along with a good skill acquiring (see Figure 6).
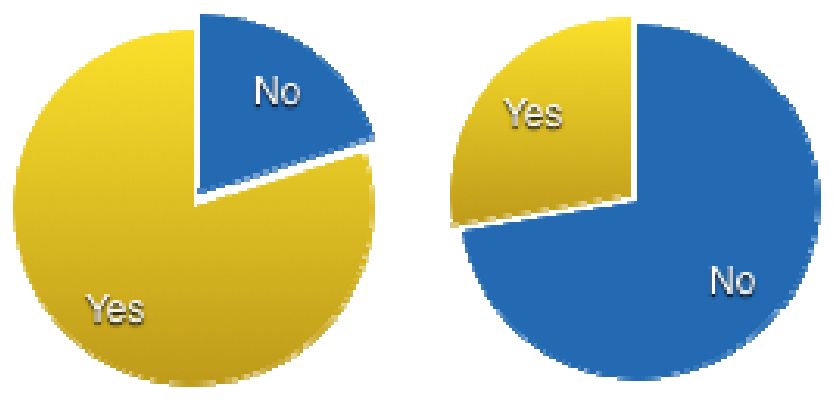

Figure 6. Students' answers to question-Is the soil a renewable resource? (The left pie show before playing SoilQuest and the right pie show after playing).

In children aged 9-14, SoilQuest proved to be a great tool of engage, introducing the topic and capturing the students' interest (Maraffi et al., 2016a; 2016b).

Figure 7 showed that the attention rate for the frontal lesson and the one related to the multi-media lesson are similar (Maraffi \& Paris, 2017). The multi-media activities (PPT supported) allow only a degree of attention slightly larger. This may be the contribution of the multi-media tool, which increases the perception. The student perception increases but it has the same small attention duration and the same drop out.

Instead, the CCRPG allows a significantly greater attention, with a persistent attention during the whole game.

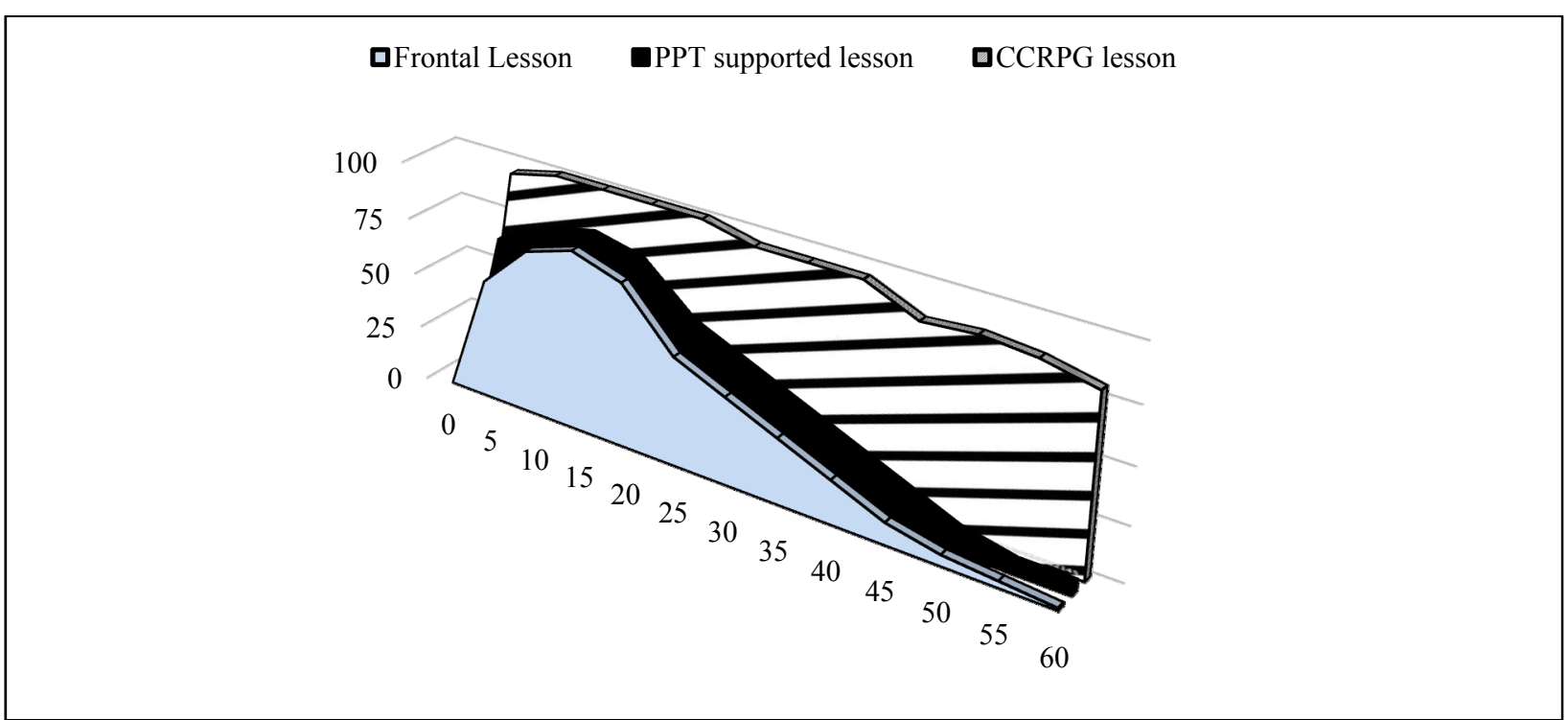

Figure 7. Percentage of attention level measured after frontal teaching activity (tint color), after multi-media teaching activities supported by PPT (dark color), and after GeoQuest teaching activities (stripe). Average calculated on 26 classes.

\section{Discussion}

Experimental observation evidences show that CCRPG seems to be the most effective game based learning typology to improve student learning. Digital storytelling enhances a student engagement, in agreement with Akkerman, Admiraal, and Huizenga (2009) which found that storifying history using mobile 
games had a positive effect on student engagement. Aktas and Yurt (2017) found that digital storytelling has a positive effect on permanent learning, too.

The results obtained at the moment confirm that the approach LoG proposed through the CCRPG GeoQuest improves both integrated development of basic skills and European key competences:

1. Communication in one's mother-tongue: through storytelling;

2. Communication in foreign languages: multi-language game matches CLIL approach;

3. Skills in math and science: scientific topics;

4. Digital skills: use of computers, tablets, and smartphones to play the game and for interaction;

5. Learning to learn: inquiry and problem-solving;

6. Social and civic responsibility: group activities, collaborative learning, and peer tutoring;

7. Initiative and entrepreneurship: organisation of inquiry resolution paths as a group;

8. Cultural awareness: multi-disciplinary pathways aimed at overcoming the dichotomy between science and cultural expressions (humanities).

The game features can be a vehicle for situated learning and support a personalised learning (different communication codes and different modality to convey complex topics). Teachers feel themselves motivated and excited, because the CCRPG GeoQuest is not limited to a specific school-age range, but it got very satisfactory results from students aged 8-21. GeoQuest has the following strengths:

1. It ensures collaborative learning: All students follow the game play on a single screen and the EVO-Quest engine proceeds according to the answer majority;

2. It fosters peer collaboration: Each student interacts through their own devices, but the game progress and scores depend on the student group roles. A healthy competition arises among different groups within the single class;

3. It guarantees immediate feedback: Gaming system immediately reports the outcome of responses and shows the exact answer with explanations;

4. It Avoids failure mortification: Each player can see and understand his errors but these are not made known to the other players;

5. It gives well engage: Storytelling, adventure atmosphere, and insertion of some fantasy elements inside the story;

6. It is a good tool for innovative teaching: It combines ICT, situated learning, laboratory activities, correct use of smartphones and tablets;

7. It is ideal for teaching with content and language integrated learning (CLIL) methodology: The narrative voice, the subtitles, and the proposed activities are provided in several different languages (more than $30)$;

8. It is inclusive: The accessible design creates an inclusive learning environment. Every adventure has specific notebooks (compensatory instruments) and multi-sensor stimuli (assistive instruments);

9. It is ideal for skills assessment: Real-life tasks, dealt with "in situation" (Maraffi \& Marinelli, 2016).

We can conclude that it is not the multi-media tool itself to give a more profitable learning environment, but the engaging and the interactivity (see Figure 7).

\section{Conclusion and Future Plans}

GeoQuest is a CCRPG specifically designed for LoG aimed at learning while playing. This new approach 
fosters skills acquiring and supports personalised learning. It could improve the student learning levels, motivate teachers, and renew teaching methodologies.

The results obtained in the early stages of the research are pushing for the creation of new adventures and a definitive quantitative experimentation. The project achievement in the dissemination was excellent and we also received a high number of collaboration requests on new projects. We can apply GeoQuest to expanded forms of education, such as digital heritage and tourism, to teach security and safety, and new topics, such as medicine or astronomy.

\section{References}

Abrantes, S., \& Gouveia, L. (2012). Using games for primary school: Assessing its use with flow experience. In M. M. Cruz-Cunha (Ed.), Handbook of research on serious games as educational, business, and research tools (pp. 769-781). Pennsylvania: IGI Global.

Akkerman, S., Admiraal, W., \& Huizenga, J. (2009). Storification in history education: A mobile game in and about medieval Amsterdam. Computers \& Education, 52(2), 449-459.

Aktas, E., \& Yurt, S. U. (2017). Effects of digital story on academic achievement, learning motivation, and retention among university students. International Journal of Higher Education, 6(1), 180-196.

Bursztyn, N., Pederson, J., Shelton, B., Walker, A., \& Campbell, T. (2015). Utilizing geo-referenced mobile game technology for universally accessible virtual geology field trips. International Journal of Education in Mathematics: Science and Technology, 3(2), 93-100.

Bursztyn, N. Shelton, B., Walker, A., \& Pederson, J. (2016). Increasing undergraduate interest to learn geoscience with GPS-based augmented reality field trips on students' own smartphones. GSA Today, 27(6).

Chapman, J. R., \& Rich, P. (2017). Identifying motivational styles in educational gamification. In Proceedings of the 50th Hawaii International Conference on System Sciences, Hawaii, USA.

Cohen, P. (2016). Digital game-based learning: Effects on students' perceptions and achievements in a business process management course (Ph.D. dissertion, WITS School of Economic \& Business Science, University of Witwatersrand, Johannesburg, South Africa).

Csikszentmihalyi, M., \& Schneider, B (2000). Becoming adult: How teenagers prepare for the world of work. New York, N.Y.: Basic Books.

Fassbender, E., Richards, D., Bilgin, A., Thompson, W. F., \& Heiden, W. (2012). Vir-school: The effect of background music and immersive display systems on memory for facts learned in an educational virtual environment. Computers \& Education, $58(1), 490-500$.

González-González, C. S., Collazos, C. A., Guerrero, L. A., \& Moreno, L. (2016). Game-based learning environments: Designing the collaborative learning processes. ACTA Scientiae, 18(4), 12-28.

Hamari, J., Shernoff, D. J., Rowe, E., Coller, B., Asbell-Clarke, J., \& Edwards, T. (2016). Challenging games help students learn: An empirical study on engagement, flow and immersion in game-based learning. Computers in Human Behavior, 54, 170-179.

Hwang, G. J., Chiu, L. Y., \& Chen, C. H. (2015). A contextual game-based learning approach to improving students' inquiry-based learning performance in social studies courses. Computers \& Education, 81, 13-25.

Jantke, K. P., \& Hume, T. (2015). Effective learning through meaning construction in digital role playing games. In IEEE International Conference on Consumer Electronics (ICCE). Las Vegas, USA.

Lepper, M. R., \& Hodell, M. (1989). Intrinsic motivation in the classroom. In Research in motivation in e-education (Vol. 3, pp. 73-105). San Diego, C.A.: Academic Press.

Maraffi, S., Scamardella, A., \& Sacerdoti, F. M. (2015). GeoQuest: A class interactive role-playing game. In EGU General Assembly (Eds.), Geophysical Research Abstracts. Wien: EGU.

Maraffi, S., \& Scamardella, A. (2016). GeoQuest Vesuvius an inter-disciplinary role-playing game. In New Perspectives in Science Education International Conference Proceedings (pp. 342-346). Firenze, Italy.

Maraffi, S., Sacerdoti, F. M., \& Scamardella, A. (2016). GeoQuest Vesuvius a class role playing game. In STEAM Education Proceedings: Hawaii University International Conferences, Hawaii, USA.

Maraffi, S., \& Marinelli, A. L. (2016). ValuQuest: A role-playing game for skills assessment. In STEAM Education Proceedings: Hawaii University International Conferences, Hawaii, USA. 
Maraffi, S., \& Sacerdoti, F.M. (2016). GeoQuest project: Computer class role-playing game as innovative teaching methodology to foster STEAM education. Journal of Environmental Science and Engineering, 5(10), 495-511.

Maraffi, S., Pennesi, D., Acqua, A., Stacchiotti, L., \& Paris, E. (2016a). SoilQuest: A computer class role-playing game. Online Reports of Italian Geological Society, 40(1), 969. Roma: Società Geologica Italiana.

Maraffi, S., Pennesi, D., Acqua, A., Stacchiotti, L., \& Paris, E. (2016b). SoilQuest: An IBSE approach with computer class role-playing game. International Journal of Research and Innovations in Earth Science, 3(5), 88-91.

Maraffi, S., \& Sacerdoti, F. M. (2016). GeoQuest: A computer classroom role-playing engine to teach earth science in an inter-disciplinary way. In The 9th annual International Conference of Education, Research and Innovation (pp. 6119-6127). Seville, Spain.

Maraffi, S., Ercolino, I., \& Sacerdoti, F. M. (2017). Who killed Maya Foster? A CLIL CrimeQuest, interactive computer class role playing game. In European Festival Science on Stage Inventing the Future of Science Education, Debrecen, Hungary.

Maraffi, S. Pennesi, D., Acqua, A., Stacchiotti, L., \& Paris, E. (2017). Soil is a resource: Three teaching methods to achieve one target. In The 12th Conference of the European Science Education Research Association (ESERA), Dublin, Ireland.

Maraffi, S., \& Paris, E. (2017). Learning on gaming (LoG) improves integrated development of basic science skills and fosters curiosity towards the earth sciences. In Congress geosciences: A tool in a changing world. Italy: PISA.

Martínez-Rodríguez, J. (2011). Métodos de investigación cualitativa (Qualitative research methods). Revista de la Corporación Internacional para el Desarrollo Educativo (Magazine of the International Corporation for Educational Development), 8.

Martínez-Godínez, V. L. (2013). Paradigmas de investigación: Manual multimedia para el desarrollo de trabajos de investigación (Research paradigms: Multimedia manual for the development of research projects). Retrieved from https://s3.amazonaws.com/academia.edu.documents/38994313/7_Paradigmas_de_investigacion_2013.pdf?AWSAccessKeyI $\mathrm{d}=$ AKIAIWOWYYGZ2Y53UL3A\&Expires $=1512386400 \&$ Signature $=$ CBKEXeF9c\%2FEPkPWXIP4IMyzCRCo\%3D\&resp onse-content-disposition=inline\%3B\%20filename\%3D7_Paradigmas_de_investigacion_2013.pdf

Marty, J. C., \& Carron, T. (2011). Observation of collaborative activities in a game-based learning platform. Transactions on Learning Technologies (TLT), 4(1), 98-110.

Mayo, M. (2009). Video games: A route to large-scale STEM education? Science, 323, 79-82.

McGonigal, J. (2012). Reality is broken: Why games make us better and how they can change the world. New York, N.Y.: Penguin Press.

Parker, L. E., \& Lepper, M. R. (1992). Effects of fantasy contexts on children's learning and motivation: Making learning more fun. Journal of Personality and Social Psychology, 62, 625-633.

Sacerdoti, F. M., \& Maraffi, S. (2015). EVO-RPGE: An interactive role-playing engine. In The International Congress on Education, Innovation and Learning Technologies (ICEILT) (Vol. 2, p. 148). Granada, Spain.

Vygotsky, L. S. (1978). Mind in society: The development of higher psychological processes. Cambridge: Harvard University Press. 